\title{
A ficção científica como elemento de problematização na educação em ciências
}

\section{Science fiction as problematization element in science education}

Resumo: Neste trabalho pretendemos mostrar que a ficção científica pode ser trazida para o contexto da educação científica para discutir a ciência em perspectiva ampla, oferecendo conexões com o contexto social e possíveis futuros imagináveis. Para isso, realizamos um apanhado das razões dadas por autores para o uso didático do gênero, e questionamos a visão de que se trata de um simples elemento motivador de interesse. Procuramos abordar a questão do interesse trazendo as contribuições teóricas de Georges Snyders e de Paulo Freire, e, depois, apresentar a visão dos críticos especializados em ficção científica. Finalmente, articulamos ambas as perspectivas, procurando mostrar como a ficção científica possui características que justificam sua presença nas atividades educativas de ciências, com sentido efetivamente motivador, não como artifício para angariar a simpatia dos estudantes por ciência, e sim porque é capaz de apresentar questões significativas sobre as quais todos gostaríamos de nos debruçar.

Palavras-chave: Ficção científica. Educação em ciências. Crítica literária. Pedagogia crítica.

\begin{abstract}
In this work we intend to show that science fiction could be brought to science education to discuss science in a broad perspective, providing connections to the social context and to possible imaginable futures. For that, we made a list of reasons given by authors for the didactic use of the genre and wondered about the vision that it is a simple matter of stimulating students' interests. We tried approach the question of interest by bringing theoretical contributions from Georges Snyders and Paulo Freire, thereafter presenting the view of specialized science fiction scholars. Finally, we articulated both perspectives by showing how science fiction has features that justify its presence in science didactic activities, which have an effective sense of motivation, not as an artifice to gather sympathy from students toward science, but by being able to present meaningful questions about what all of us would like to approach.
\end{abstract}

Keywords: Science fiction. Science education. Literary criticism. Critical pedagogies.

\footnotetext{
${ }^{1}$ Escola de Artes, Ciências e Humanidades, Universidade de São Paulo (USP), Avenida Arlindo Bettio, 1000, Ermelino Matarazzo, CEP 03828-000, São Paulo, SP, Brasil. E-mail: <lppiassi@usp.br>
} 


\section{Especificidades da ficção científica na educação em ciências}

A ficção científica tem sido apresentada, por diversos autores, como uma possibilidade interessante na educação em ciências. Em um artigo anterior (PIASSI, 2013), apresentamos um levantamento de trabalhos (BORGWALD; SCHREINER, 1993; BRAKE; THORNTON, 2003; DARK, 2005; DUBECK; TATLOW, 1998; DUBCEK et al., 1990, 1993; FRAKNOI, 2003; FREUDENRICH, 2000; MARTÍN-DÍAZ et al., 1992; NAUMAN; SHAW, 1994; SHAW; DYBDAHL, 2000; SOUTHWORTH, 1987) que defendem o uso da ficção científica no ensino de ciências; e discutimos, a partir de alguns teóricos críticos do gênero, sua relação com o conhecimento científico no que se refere aos possíveis desdobramentos educacionais. No presente trabalho, nossa preocupação maior é fundamentar as razões para a presença da ficção científica nas diversas modalidades de educação em ciências, em função de suas potencialidades problematizadoras. No artigo anterior mencionado, apresentamos o excerto do trabalho da pesquisadora espanhola de educação científica M. J. Martín-Díaz e sua equipe de professores colaboradores:

Acreditamos fortemente que a ficção científica pode ser um instrumento muito útil para nos auxiliar a atingir alguns objetivos na educação científica, tais como elevar a motivação e o interesse dos estudantes, desenvolver atitudes positivas perante a ciência, ajudar a criar conflitos cognitivos e promover a criatividade e o questionamento crítico. (MARTÍN-DÍAZ et al., 1992, p. 22, tradução nossa)

Nesse trecho, temos quatro diferentes categorias de razões para o emprego da ficção científica, que podemos descrever da seguinte maneira:

(1) Motivação - O uso da ficção científica se justifica por um suposto interesse que ela é capaz de despertar nos estudantes.

(2) Atitudes - A ficção científica é vista como uma forma de produzir uma relação positiva do estudante com a cultura e o conhecimento científicos.

(3) Cognição - A ficção científica auxiliaria os estudantes no processo de aprendizagem de conceitos científicos.

(4) Habilidades - Algumas habilidades, tais como a criatividade e o pensamento crítico, consideradas importantes na educação científica seriam incentivadas pelo uso da ficção científica.

A primeira das razões parece ser uma espécie de consenso entre os autores que propõem o emprego da ficção científica em atividades de educação em ciências. Na maior parte dos casos, a intenção de tais autores parece ser a conversão de um suposto interesse dos educandos na ficção científica em um genuíno interesse pela ciência em si. Esse ponto de vista é explicitado, por exemplo, por autores como a historiadora Ann K. Naumann e o professor de ciências Edward L. Shaw (NAUMANN; SHAW, 1994), assim como pelo biólogo e divulgador de ciências Craig Freudenrich (2000, p. 42). Nenhum dos autores, entretanto, apresenta evidências de que os estudantes possuíam especial interesse pela ficção científica, nem apresentaram resultados que confirmem claramente que ele se converte em interesse pela ciência. Embora, igualmente, não tenhamos dados concretos sobre esse ponto específico, nos parece razoável supor que existe uma correlação significativa entre interesse por ciência e por ficção científica, e que estudantes que apresentem especial aversão por uma delas, frequentemente, apresentarão 
a mesma atitude em relação à outra. E, embora quase todos os autores coloquem o despertar do interesse como uma das razões para o uso didático da ficção científica, não vimos nenhum trabalho que tenha se debruçado por confirmar ou sustentar de forma sólida tal afirmação. Mas, se a questão motivacional é complexa de se abordar, entendemos ser possível colocá-la em outros termos. Não se trata de verificar simplesmente se um ou outro material aproveitado em atividades didáticas desperta ou não o interesse dos estudantes por ciência, mas de investigar mais a fundo o significado dessa proposição.

Acreditamos que seja possível colocar as coisas de outra forma. A maior parte dos autores relaciona o aspecto motivacional às demais razões que são defendidas para a ficção científica nas atividades didáticas de ciências. As razões motivacionais são apresentadas em relação bastante próxima às atitudinais e, também, como um auxílio importante em relação ao aprendizado conceitual, conforme sugerido por Martín Díaz et al. (1992, p. 18), e por entusiastas do uso didático da ficção científica, como o astrônomo Andrew Fraknoi (2003, p. 113), e o professor de física Leroy W. Dubeck (DUBECK et al., 1993, p. 47), que publicaram diversos trabalhos sobre o assunto. Esse último autor e sua equipe, porém, desenvolvem, com mais detalhes, os argumentos para o uso didático da ficção científica. Embora as razões apresentadas por Dubeck et al. (1993) possam ser enquadradas nas quatro categorias que acabamos de definir, esses autores apontam outros aspectos que merecem atenção. Em seu artigo, eles incluem, entre os aspectos desejáveis para o uso didático da ficção científica, "a compreensão da ciência tanto como um processo racional quanto um processo de descoberta" e "o posicionamento da ciência em um cenário dramático e seu relacionamento com questões socialmente relevantes" (DUBECK et al., 1993, p. 47, tradução nossa). É na direção proposta por esses autores que acreditamos que a discussão sobre o uso da ficção científica como um recurso de ensino adquire maior consistência. Em trabalhos anteriores (PIASSI, 2012, 2013), propusemos que o currículo de ciências pode englobar mais do que o estudo de conceitos, leis e fenômenos.

Para isso, baseados nas proposições trazidas pelo professor João Zanetic (1989), em sua tese "Física também é cultura", e na estruturação da didática proposta pelo pedagogo José Carlos Libâneo (1990), consideramos o saber a ensinar estruturado em três esferas: Conceitual e fenomenológica (C): leis, fenômenos, conceitos, experimentos, em outras palavras, os produtos de conhecimento da ciência; Metodológica e Histórica $(\mathrm{M})$ : a história, os métodos da ciência e sua epistemologia, ou os processos de produção do conhecimento; Social e Política (S): as relações entre a ciência e outros campos da sociedade e cultura humanas.

Sob esse ponto de vista, alguns conteúdos que Dubeck et al. (1993, p. 47) propõem, por meio da ficção científica, enquadram-se nas esferas que denominamos $\mathrm{M}$ e S, muito embora eles não tenham aprofundado tais aspectos em seu artigo. Um ponto interessante considerado por esses autores (DUBECK et al., 1990, 1993) é que situações retratadas em filmes são geralmente complexas, relacionadas a problemas da vida real, que requerem um enfoque interdisciplinar. Uma visão análoga é apresentada por Freudenrich (2000, p. 44, tradução nossa), para quem a ficção científica estabelece um pano de fundo conceitual em que "princípios científicos [...] cruzam diversas disciplinas".

Tal análise, no entanto, não terá significado efetivo se não se aproximar de uma outra questão: por que ficção científica em particular? Alguém poderia propor, como de fato fazem, o uso dos desenhos animados ou, então, de anúncios de propaganda na educação em ciências, usando exatamente os mesmos quatro argumentos empregados para justificar o uso da ficção 
científica. Um exemplo é o trabalho das professoras Donna Shaw e Claudia Dybdahl (SHAW; DYBDAHL, 2000), em que propõem, além da ficção científica, o uso de produtos de mídia como: jornais, desenhos animados e propagandas televisivas. Consideramos que tais propostas podem, efetivamente, contribuir na educação científica. A questão é se a ficção científica possui características particularmente interessantes que justifiquem seu uso no lugar de outros materiais instrucionais, ou se, ao contrário, trata-se de apenas mais uma possibilidade entre tantas outras. Uma tentativa de lidar com tal problema pode se iniciar a partir da seguinte afirmação de Nauman e Shaw (1994, p. 18, tradução nossa): “a ficção científica nos dá uma ideia de como decisões que fazemos hoje podem afetar nossa vida no futuro".

Essa talvez possa ser uma contribuição mais específica da ficção científica para a educação em ciências. Segundo Nauman e Shaw (1994), a ficção científica ajuda a pensar no futuro em função dos atuais problemas sociais, em um contexto em que ciência desempenha um papel fundamental. Porém, há outros meios de se discutir o futuro, além da ficção científica, por exemplo: os debates, as análises publicadas em jornais, as previsões de cientistas etc. Questões ambientais, como o aquecimento global, por exemplo, estão presentes todos os dias no jornal, televisão, e assim por diante; e um educador pode promover esses debates em uma situação educativa sem qualquer referência a obras de ficção. Mas o que Andrew Fraknoi (2002) defende é que a experiência da leitura de uma situação fictícia supera o aspecto meramente informativo, ao colocar o leitor na própria cena dos acontecimentos, e, dessa forma, pode representar uma importante contribuição ao aprendizado: "uma coisa é entender em princípio que o dia e a noite na Lua duram cerca de duas semanas terrestres, outra bem diferente é ler sobre um astronauta do futuro abandonado na Lua, para o qual isso se torna uma questão de vida ou morte" (FRAKNOI, 2002, p. 113, tradução nossa). É a partir desse ponto que entendemos ser possível rearticular as razões para o uso da ficção científica. Porque Fraknoi não está apenas tratando da ficção científica naquilo em que ela é única - seu voo de imaginação especulativa - mas, também, da experiência do leitor diante disso, de como ele ingressa nesse mundo de fantasia que potencializa o real. É nessa experiência que desejamos focar, procurando recolocar a noção de interesse e motivação em outros termos. Para isso, entendemos que o conceito de satisfação cultural, trazido por Snyders (1988), desempenha um papel fundamental, que discutiremos a seguir.

\section{Ciência, ficção e satisfação cultural: uma análise a partir de Snyders}

O pedagogo francês Georges Snyders (1988) propõe que a escola deve ser um espaço da passagem da cultura primeira para a cultura elaborada, e que a satisfação cultural seja o centro das preocupações pedagógicas. Seu trabalho lançou bases para uma investigação dos conteúdos como cultura e da cultura como forma de prazer, como busca de uma realização por parte do estudante. Mais do que apenas trazer uma visão crítica, uma instrumentalização ou conscientização, os conteúdos culturais, em Snyders (1988), são vistos como uma fonte de satisfação. A motivação da busca do estudante pela compreensão vem dessa satisfação que a cultura elaborada pode lhe proporcionar. O autor inicia sua exposição descrevendo o que ele denomina cultura primeira: 
Há formas de cultura que são adquiridas fora da escola, fora de toda autoformação metódica e teorizada, que não são o fruto do trabalho, do esforço, nem de nenhum plano: nascem da experiência direta da vida, nós a absorvemos sem perceber; vamos em direção a elas seguindo a inclinação da curiosidade e dos desejos; eis o que chamarei de cultura primeira. (SNYDERS, 1988, p. 23)

A noção de cultura primeira é fundamental na compreensão da ideia de satisfação cultural que será desenvolvida. Os elementos culturais que estão presentes espontaneamente no ambiente dos estudantes formam um sistema cultural complexo, repleto de nuances e de fragmentos provenientes de diversas fontes e extremamente variáveis de acordo com o contexto social. A televisão, o trabalho, os meios de comunicação, os ambientes que os jovens frequentam, as relações familiares, tudo isso contribui na formação dessa matriz. Parece inegável que a ficção científica é um dos grandes meios da veiculação de ideias a respeito da ciência, seja em filmes, livros, desenhos animados, quadrinhos ou outras mídias. Hoje em dia, expressões como força gravitacional, campos de força, neutrinos, feixes de partículas não são restritas a um público com formação científica. Ao contrário, dado o caráter popular dessas manifestações culturais, tais expressões e ideias passam a ser incorporadas ao que Snyders (1988) denomina de "cultura primeira".

São elementos dessa cultura primeira que fornecem o que Snyders chama de "alegrias simples" (SNYDERS, 1988, p. 24). Como exemplo, o autor imagina uma pessoa se divertindo na água de uma praia ou piscina, desfrutando um momento de lazer. Ou, ainda, o interesse dos jovens em motocicletas, que representam valores como: a liberdade, a vida ao ar livre, a sensualidade e o mundo técnico, as provas e os desafios. Essas alegrias simples são, de acordo com Snyders, fontes inegáveis de satisfações legítimas; e é justamente no reconhecimento da importância dos valores que elas representam que o autor propõe um caminho de elaboração, em um processo dialético de continuidade e ruptura, partindo dessa cultura primeira, identificando seus valores, mas, também, seus limites, dados pelo ponto em que ela, por sua própria natureza, não pode satisfazer. Snyders passa, então, a expor esses limites: a pessoa que se diverte na água, possivelmente, irá querer aprender a nadar, a adquirir com a água uma relação mais hábil, mais sutil e profunda. Da mesma forma, o motoqueiro pode querer se aprofundar no âmbito técnico da mecânica e do funcionamento da moto e na esfera social das relações humanas, dos códigos de ética de grupo envolvido em seu uso. Quando isso acontece, as pessoas passam a procurar a orientação daqueles que são mais experientes, que podem trazer um nível de conhecimento a um novo patamar que permita desfrutar satisfações mais elaboradas. Essas são, de acordo com Snyders (1988, p. 25), as alegrias ambiciosas.

As alegrias simples desempenham o papel de tréguas, representando um momento em que se esquece dos problemas do dia a dia. Elas estão no lazer, na diversão, nos prazeres descompromissados. Mas a palavra trégua já embute uma ideia de provisório, efêmero, que, por isso mesmo, tem um limite, não consegue alcançar nem a profundidade nem a perenidade das formas mais elaboradas, as tais alegrias ambiciosas, que estão ligadas à cultura que Snyders (1988, p. 50) denomina cultura elaborada, cujas alegrias estão na possibilidade de guiar a própria história, individual e coletiva, "para criar o novo, novos modelos, novas relações sociais, [...] em uma sociedade onde haja a possibilidade de tomar o destino nas mãos, onde valha a pena 
compreender o que se passa". É interessante notar a conexão da cultura elaborada com o novo, com o futuro, com as possibilidades de transformação dadas pelo contexto presente. Para Snyders, o papel da escola é proporcionar o acesso à cultura elaborada, porque é essa cultura que habilita o indivíduo na tarefa transformadora. Segundo ele, é por meio da cultura elaborada, portanto, que verificamos que os sonhos individuais são uma expressão de sonhos coletivos, compartilhados não só pelos contemporâneos, mas pelo gênero humano. Não se trata de um culto à irrealidade, ao impossível, mas a uma irrealidade que ganha existência em si nos anseios coletivos da humanidade. A partir do contato com a cultura elaborada, o sonho individual adquire uma dimensão nova, de uma potencialidade latente: "quanto mais frequento os sonhos culturalmente encarnados, menos tenho a temer que meus sonhos venham a confundir minha realidade" (SNYDERS, 1988, p. 82).

Se tentarmos situar a ciência nessa lógica, imediatamente sobrevém uma justaposição entre as mudanças sociais, políticas, culturais e econômicas, imaginadas ou sonhadas, e as possibilidades de o conhecimento científico ser um fator-chave dessas mudanças. Ao mesmo tempo, estamos frente a uma relação dialética estabelecida pela dicotomia presente-futuro. O presente, representado pela situação dada, pelas vivências imediatas, pelos resultados percebidos de um processo social que se estende até o hoje. O futuro, imaginado como repleto, ao mesmo tempo, de possibilidades alvissareiras e ameaçadoras, em tensão com o presente, opondo-se a ele e, ao mesmo tempo, derivado das condições que ele coloca. O conhecimento científico, que pode ser visto tanto como uma resposta quanto como uma ameaça aos anseios humanos, vem ao encontro do sentido de futuro e de transformação do presente. Em relação ao interesse ou motivação com o conhecimento e com o aprendizado, Georges Snyders volta sua atenção ao significado de satisfação que o acesso à cultura pode proporcionar e ao papel da escola no acesso dos estudantes a essa satisfação. O pedagogo francês coloca, no centro das preocupações, a questão dos conteúdos escolares, e vincula-os à questão da cultura e a seu papel na satisfação, da alegria e do prazer:

Para dar alegria aos alunos, coloco minha esperança na renovação dos conteúdos culturais. A fonte de alegria dos alunos, não a procuro inicialmente do lado dos jogos, nem dos métodos agradáveis, nem do lado das relações simpáticas entre professores e alunos, nem mesmo na região da autonomia e da escolha: não renuncio a nenhum destes valores, mas conto reencontrá-los como consequência e não como causas primeiras. (SNYDERS, 1988, p. 13)

As possibilidades futuras, implícitas no conhecimento científico, portanto, podem ser encaradas a partir de uma perspectiva pessimista ou de uma visão otimista. Snyders analisa essas duas visões no contexto da educação escolar. O otimismo é, para ele, uma arma revolucionária: "a satisfação cultural e por conseguinte a alegria na escola só podem existir se houver uma outra cultura diferente daquela que se dedica às vidas perdidas, ao culto do insucesso que vai entravar as esperanças e as possibilidades" (SNYDERS, 1988, p. 77). Assim, o autor coloca explicitamente a questão das expectativas em relação à cultura e ao seu papel-chave na busca de um sentido, que só se configura como sentido justamente porque está vinculado a um sentido de vida. Nesse ponto, Snyders está apontando para essa questão fundamental, onde vemos uma convergência com as ideias de Paulo Freire, em torno do que denominamos problemas significativos. 


\section{A questão dos problemas significativos a partir de Snyders e Paulo Freire}

Em um livro em que é transcrito um longo diálogo com o filósofo chileno Antonio Faundez, o educador brasileiro Paulo Freire afirma que "o sonho é sonho porque, realisticamente ancorado no presente concreto, aponta o futuro, que só se constitui na e pela transformação do presente" (FREIRE; FAUNDEZ, 1985, p. 71). Para esses autores, o sonho, como constituição de possibilidades imaginadas, dadas pelo presente, é parte fundamental da existência humana: "a criação de sonhos possíveis, a luta por realizar, cristalizar esses sonhos possíveis, recriar novos sonhos possíveis à medida que esse sonho possível de alguma forma escape a sua realização absoluta" (FREIRE; FAUNDEZ, 1985, p. 71).

Portanto, ao falar de dar sentido aos conteúdos, não estamos falando apenas de uma motivação, ou de uma compreensão conceitual no sentido estrito, mas de uma interligação mais profunda com as expectativas do sujeito em relação à vida, ao mundo que o cerca. Os mecanismos por meio dos quais tais ligações são construídas é que são a chave de uma abordagem da educação científica que aponte para uma apropriação efetiva do conhecimento como valor cultural que adquire o caráter revolucionário que tanto Snyders quanto Freire propugnam. Interesse e motivação, portanto, não estão ligados apenas ao sentido de alegria e diversão. Motivar o estudante não significa simplesmente apresentar coisas agradáveis por meio de recursos lúdicos, que é o que usualmente se imagina como estratégia para interessar os alunos por ciência. Entendemos que o jovem, que deseja, sim, satisfação cultural, que almeja legitimamente ao prazer, também anseia engajar-se e dar sentido à sua trajetória de vida, de realizar grandes feitos, e que isso também integra o interesse e a motivação, talvez muito mais profundamente do que uma diversão casual.

Portanto, quando vemos educadores que introduzem a ficção científica em atividades didáticas de ciências, propondo, entre aspectos motivacionais, o "estabelecimento de um quadro contextual" (FREUDENRICH, 2000, p. 44, tradução nossa), "o posicionamento da ciência em um cenário dramático" (DUBCEK et al., 1993, p. 47, tradução nossa) ou "uma forma de predizer como a vida poderia ser em algum tempo futuro" (NAUMAN; SHAW, 1994, p. 18, tradução nossa), podemos concluir que essa motivação tem profundas características socioculturais, como forma de engajar os alunos em problemas significativos, cujo objetivo não é proporcionar entretenimento aos estudantes, mas questionar a respeito de suas vidas, das possibilidades que os tempos futuros podem nos reservar.

Acreditamos que se possa levantar questionamentos à transposição pura e simples das ideias de Paulo Freire sintetizadas em "Pedagogia do Oprimido" (FREIRE, 1987) para o contexto escolar, da educação formal, já que elas são situadas claramente pelo contexto histórico e político da época em que a obra foi concebida e, também, porque muito do que se discute ali tem indissociável filiação ao contexto específico da educação de adultos em ambiente não formal ou quase-formal. Porém, como aponta Zanetic (1989, p. 50), em Freire, a matriz epistemológica do processo de ensino-aprendizagem com a participação explícita e ativa do educando como sujeito do processo e os conceitos daí derivados são fundamentais para a compreensão da relação do sujeito com o conhecimento, tomando-se, como pano de fundo, o contexto sociocultural, ao mesmo tempo em que se leva em conta a relação educador-educando. Freire produziu, assim, uma síntese teórica que é independente do contexto particular de sua produção, por construir 
categorias que permitem conceber o processo de ensino-aprendizagem como um processo onde o educando é um sujeito não apenas do ponto de vista cognitivo, mas, sobretudo, do ponto de vista de um indivíduo inserido em um ambiente sociocultural.

Isso se articula com as concepções de Snyders (1988) sem se sobrepor a elas. O autor francês trouxe explicitamente elementos afetivos, como a satisfação e a alegria, não claramente identificáveis na obra de Freire, e enfatizou o papel da escola ao valorizar, no processo de ensino-aprendizagem, o papel do indivíduo como tal, com seus interesses, anseios e necessidades culturais próprias. Não se restringiu à visão do estudante como um oprimido, mas, também, como uma pessoa que vê, na cultura, uma fonte de satisfação pessoal, de crescimento e de respostas a questões que todos se colocam. É em Freire, entretanto, que encontramos uma maior sistematização e um maior detalhamento estrutural do processo de ensino-aprendizagem inserido no contexto sociocultural. Uma das noções fundamentais na teoria da ação dialógica de Paulo Freire, a problematização, requer, por parte dos educandos, a adesão ao processo. Salienta o autor que "adesão conquistada não é adesão, porque é 'aderência' do conquistado ao conquistador através da prescrição das opções deste àquele” (FREIRE, 1987, p. 167, grifos do autor). É, assim, que se compatibiliza com a proposição de Snyders (1988, p. 187) de que é nos conteúdos e não nos métodos que se busca a fonte da satisfação, "é a renovação dos conteúdos que suscita a renovação dos métodos, das relações entre professores e alunos, das obrigações e de disciplina". É no sentido em si que esses conteúdos representam, e não por uma motivação de ligação com o real que procure conquistar a aderência dos estudantes ao processo, porque a simples necessidade de tal artifício revela um processo, no falar de Freire, antidialógico, onde o estudante não é mais sujeito, mas objeto. Para Freire (1987, p. 70):

Quanto mais se problematizam os educandos como seres no mundo e com o mundo, tanto mais se sentirão desafiados, quanto mais obrigados a responder ao desafio. Desafiados, compreendem o desafio na própria ação de captá-lo. Mas, precisamente, porque captam o desafio como um problema em suas conexões com outros, num plano de totalidade e não como algo petrificado, a compreensão resultante tende a tornar-se crescentemente crítica, por isto, cada vez mais desalienada.

A problematização se dá partindo dos elementos da cultura primeira (nas palavras de Snyders), em um processo de ação-reflexão (nas palavras de Freire) sobre o universo trazido por essa cultura. Os desafios são captados na medida em que se mostram dotados de sentido no contexto da cultura primeira, dos anseios e preocupações que ela suscita em direção a um "saber-mais". Trata-se de um caminho que não nega a cultura primeira, mas assenta suas bases sobre ela e se constrói a partir dela. Esse é o processo que dá origem ao conceito de curiosidade epistemológica, que João Zanetic discute, a partir de Freire:

Um fator determinante no encaminhamento de um jovem para o encantamento com o conhecimento, para o estabelecimento de um diálogo inteligente com o mundo, para a problematização consciente de temas e saberes, é a vivência de um ambiente cultural rico e estimulador, que 
possibilite o despertar da curiosidade epistemológica. (ZANETIC, 2005, p. 21, grifo do autor)

Cabe, então, se perguntar como pode se dar a criação desse ambiente culturalmente rico e estimulador. Mas, se como dissemos, não é uma simples questão de como ensinamos, mas do que ensinamos, o que devemos ensinar afinal, para podermos produzir esse encantamento, essa curiosidade epistemológica e essa satisfação cultural de que nos falam os autores?

Sobre isso, o pedagogo francês pergunta: "O que é ensinado corresponde às expectativas dos alunos? Acolhe suas preocupações? Amplia sua experiência vivida? Quais relações são mantidas com as perguntas que eles fazem a si mesmos?" (SNYDERS, 1988, p. 190). Se assumirmos que interesses dos alunos são aqueles que respondem às suas preocupações, e que o papel da escola - e da educação científica de modo geral - é trazer essas questões à pauta e fornecer novas maneiras de lidar com elas por meio dos conteúdos culturais, decorre que a ficção científica pode desempenhar um papel na educação científica, não como um método atraente para facilitar o aprendizado de conceitos ou leis da natureza, mas porque fornece maneiras de pensar sobre estes conceitos e leis a partir dos problemas estabelecidos pelas práticas sociais. Vejamos, então, como esse mecanismo se dá, naquilo que é específico da ficção científica.

\section{Problematização com ficção científica: contribuições da crítica literária}

Uma história de fantasia pode proporcionar entretenimento e, ao mesmo tempo, trazer algumas questões da vida real por meios alegóricos. Proporciona um encantamento que pode ser associado ao desejo de conhecer mundos maravilhosos e seres estranhos. Uma história realista, por outro lado, aponta diretamente para a vida atual ou passada, levando a uma reflexão sobre o mundo dado mais do que a conjecturas sobre possibilidades. Não há dúvida de que tanto a literatura quanto o cinema, em geral, podem ser materiais interessantes em atividades didáticas, mas a ficção científica é, por excelência, o gênero em que as questões socioculturais sobre a ciência são sistematicamente apresentadas como base para a produção ficcional. A boa história de ficção científica cria ligações da vida real às preocupações que temos sobre o nosso futuro, considerado o nosso presente.

Pensamos que, se a ficção científica possui características especiais no contexto da educação em ciências, elas estão localizadas na confluência de duas características: é fortemente baseada nas práticas sociais envolvidas com a ciência e as suas consequências futuras e, ao mesmo tempo, envolve os leitores em um mundo fictício, dando-lhes uma sensação vivencial detalhada da situação retratada. Neste sentido, concordamos com Brake e Thornton (2003, p. 31, tradução nossa):

[...] a ficção científica não existe apenas como um gênero de textos e filme interessantes, mas como um fenômeno cultural que incentiva uma forma imaginativa de observação e interpretação do mundo. 
Para reforçar essa hipótese, vejamos o que diz a crítica literária de ficção científica.

John Brunner (1971), um escritor conhecido de ficção científica, já em 1971 defendeu que a ficção científica teria um papel importante no ensino da ciência. Seus argumentos baseavam-se numa afirmação fundamental:

A ficção científica deve ser claramente entendidaa, não é ficção sobre a ciência. É sobre pessoas, como toda ficção - embora, neste caso específico eles possam muito bem não ser humanos - que se beneficiam ou são afetadas pelo impacto da mudança tecnológica. (BRUNNER, 1971, p. 389, grifo do autor, tradução nossa)

Assim, Brunner (1971) destaca que ficção científica é ficção e trata essencialmente de pessoas em vez de coisas, descobertas ou fenômenos. Como um gênero de ficção, no entanto, deve ter algumas características específicas que a definem em contraste com outros gêneros. Brunner nos dá algumas dicas do que tais características específicas possam ser: algo relacionado a "impactos da mudança tecnológica".

O crítico literário especializado em fantasia e ficção científica, Eric Rabkin (1977), tenta defini-lo em uma forma mais precisa, a partir de análises dada por outros autores no contexto da crítica de gêneros, sobretudo distinguindo a ficção científica de manifestações literárias similares. Para ele, a obra é "ficção científica se o seu mundo narrativo é, pelo menos, um pouco diferente do nosso, e se essa diferença se revela contra o fundo de um corpo organizado de conhecimento" (RABKIN, 1977, p. 119, tradução nossa). Ele termina sua definição com várias explicações, das quais destacaremos dois aspectos:

1. Os elementos normalmente associados à ficção científica, como naves espaciais, armas de raios e raças alienígenas, não são importantes para definir o gênero (RABKIN, 1977, p. 121). Em vez disso, é central o pressuposto de um mundo ordenado, regido por leis naturais que poderiam ser racionalmente formuladas. Rabkin usa um argumento kuhniano (KUHN, 1975), para defini-lo em termos de paradigmas que, embora ficcionais, formam um pano de fundo racional sobre o qual os fatos e os fenômenos são retratados.

2. O poder heurístico (RABKIN, 1977, p. 121) das narrativas de ficção científica, que prevê formas de imaginar diferentes possibilidades em contraste com o nosso mundo real, e, ao mesmo tempo, dá nova compreensão sobre como este "mundo real funciona". (RABKIN, 1977, p. 121)

De forma semelhante, a escritora e crítica literária britânica Christine Brooke-Rose (1981) tenta definir o alcance da ficção científica. Ela parte da conhecida teoria formalista do linguista búlgaro Tzevan Todorov (2004), a respeito do gênero fantástico, confrontando-a à abordagem marxista do crítico literário croata especializado em ficção científica, Darko Suvin (1984). Brooke-Rose busca evitar tanto a restrição a aspectos formais do texto, característica do primeiro autor, quanto o que ela vê como uma metodologia excessivamente avaliativa do segundo. Ela reúne contribuições de diversos autores e obras sobre as controvérsias de se a ficção científica está mais relacionada à ficção realista ou à narrativa maravilhosa, como propõe Todorov. Sua conclusão é que, a partir de pontos de vista diferentes, ambas as visões são corretas. A relação da ficção científica para a realista é, segundo ela, "sua falta de imaginação 
no que diz respeito à técnica narrativa, por oposição à sua imaginação no que diz respeito às ideias" (BROOKE-ROSE, 1981, p. 82, tradução nossa).

Autores formalistas defendem abordar a ficção em sua estrutura, considerando os elementos presentes na história em uma interpretação literal. Ao mesmo tempo, consideram os textos literários como tendo as suas leis próprias, que devem ser analisados de forma independente de seu contexto de produção. Uma posição tão rigorosa não é muito compatível com a ideia de que o gênero retrata as práticas sociais relativas à ciência e tecnologia, mas tem o mérito de descrever os procedimentos de ficção e as relações entre os elementos de uma história. Outra posição é a de que toda a ficção, incluindo a ficção científica, versa sobre os problemas de hoje, conforme aponta a crítica literária Mary Talbot (1995, p. 6, tradução nossa), quando afirma que "narrativas ficcionais podem ser consideradas como resolução imaginária de contradições reais". Portanto, em uma história de ficção científica, devemos considerar os elementos de um ponto de vista alegórico, relacionados com o contexto social de sua produção. Considerando que tal procedimento esvazia do seu poder de conjecturar sobre o futuro, ela enfatiza o fato de o gênero aludir ao mundo real, e não a um futuro imaginável.

Para Suvin (1984), a cognição é o aspecto central da ficção científica. Ele desenvolve essa ideia a partir do conceito de estranhamento cognitivo que Bertold Brecht (1973 apud SUVIN, 1984, p. 29) apresentou em seu "Pequeno Organon para o Teatro". Nesse trabalho, o diretor de teatro alemão exemplifica a ideia partindo do conhecido episódio quando Galileu Galilei, durante uma missa em uma catedral, observa a oscilação de um candelabro e as suas medições de período usando sua pulsação como referência, e concluindo que seu período não depende da amplitude de oscilação. A forma como Galileu observou tais fenômenos prosaicos configura um distanciamento do cotidiano comum de observação. A oscilação adquiriu, para o olho do observador, uma nova qualidade: um fato corriqueiro se transformou em algo espantoso. Essa admiração, porém, ao invés de permanecer como um simples sentimento ou sensação, conduziu a uma nova compreensão sobre as leis que regem os fenômenos. Esse tipo de efeito, de acordo com Suvin (1984), é o que uma boa história de ficção científica proporciona aos seus leitores.

É interessante notar que tal ideia é semelhante ao que diz Aristóteles, em sua obra "Metafísica", sobre a origem da filosofia: "os homens começaram a filosofar, agora como na origem, por causa da admiração" (ARISTÓTELES, 2005, p. 11). Aqui, a palavra admiração (no original grego, thaumazein ou $\theta a u \mu a ́ \zeta \varepsilon v v$ ) pode ser interpretada como espanto ou surpresa. Ao mesmo tempo, poderia significar uma pergunta, um desejo de aprender ou compreender alguma coisa em uma situação em que uma dúvida surge. A definição dada assemelha-se muito à cognição de Suvin (1984) e ao poder heurístico proposto por Rabkin (1977). Em todos os casos, estamos a considerar um efeito supostamente presente na ficção científica, que reproduz uma espécie de sentimento e atitude frente ao mundo natural, necessário para obter uma melhor compreensão sobre o assunto. Acreditamos que a ficção científica atinge tal efeito, em parte devido à sua retórica do real, como Brooke-Rose (1981) pontua. A ficção científica segue, de perto, a forma realista de contar histórias, enquanto apresenta, ao leitor, uma situação que é claramente diferente da realidade, conforme salienta Rabkin (1977). Embora esse efeito não seja produzido por uma hesitação entre o racional e o sobrenatural, como propõe Todorov (2004) em relação ao gênero fantástico, ainda assim há uma espécie de hesitação, mas essa ocorre entre a possibilidade e a impossibilidade. O famoso escritor de ficção científica Isaac Asimov, 
por exemplo, afirma que no gênero não há ciência verdadeira nem ciência falsa, mas sim uma ciência que poderia ser verdade (ASIMOV, 1984, p. 27).

Há uma disputa entre passado e futuro, uma espécie de experiência ímpar sobre o tempo histórico, que parece ser uma chave para compreender a ficção científica. De acordo com Jameson (2005, p. 345, tradução nossa), "a ficção científica é geralmente entendida como a tentativa de imaginar futuros inimagináveis. Mas seu mais profundo assunto pode, de fato, ser o nosso próprio presente histórico". Por outro lado, para Umberto Eco (1989, p. 169), a ficção científica é "um gênero autônomo, quando a especulação contrafactual de um mundo estruturalmente possível é conduzida extrapolando, de algumas linhas de tendência do mundo real, a possibilidade mesma do mundo futurível”. Embora pareçam visões inconciliáveis sobre a ficção científica, consideramos ambas adequadas e complementares, não como simples visões sobre a natureza do gênero, mas em relação aos pontos essenciais que dão à ficção científica um interesse especial para a educação científica. A ficção científica é sobre o futuro e, também, sobre o presente. Esta é sua ambiguidade principal e, também, sua vocação problematizadora. Assim, ao invés de adotar uma ou outra posição extrema, é preferível, como diz Brooke-Rose (1981, p. 78), o caminho do meio que é, do nosso ponto de vista, o que conserva a heurística, o poder essencial, conforme definido por Rabkin (1977), que tem consequências educacionais que gostaríamos de explorar como possíveis respostas às questões que colocamos a partir de Snyders e Freire.

\section{Considerações finais}

Após essa discussão, podemos estabelecer um novo olhar sobre as razões que educadores e pesquisadores em educação científica dão para levar a ficção científica para as aulas de ciência e outras atividades didáticas em educação científica. Iniciamos o trabalho listando e questionando quatro categorias de motivos para esse procedimento. Talvez devêssemos acrescentar um novo tipo de motivação: a social. Shaw e Dybdahl (2000, p. 22, tradução nossa) apontam que as crianças não aprendem ciência apenas na escola: "esta aprendizagem inclui os seus encontros com a ciência na mídia não impressa, tais como filmes, programas de televisão e anúncios publicitários de televisão e mídia impressa, como jornais, revistas e livros”. Elas argumentam que essa aprendizagem informal é um fato inevitável e, por isso, os educadores devem estar preparados para levar em conta as interações entre a aula de ciências do ensino formal e informações de outras fontes que as crianças obtêm. A ciência está presente nos meios de comunicação, simplesmente porque, cada vez mais, toma parte na nossa vida sociocultural como um todo. Para a estudiosa de mídia holandesa, J. Van Dijck (2003, p. 183, tradução nossa), "temos de reconhecer como todo o aparato de entretenimento audiovisual de massa é mais que um simples mediador, é um importante espaço onde a construção e constituição da ciência são negociadas". Neste contexto, a ficção científica tem um lugar especial. Deste ponto de vista, não deve ser considerada como um simples auxílio de ensino, mas como uma fonte de questões atuais e as preocupações sobre o papel da ciência e da tecnologia em nossa sociedade, a "resolução imaginária de contradições reais" visualizada por Talbot (1995, p. 6).

Voltemos, pois, à questão inicial, propondo um exemplo. Imaginemos o romance "A Máquina do Tempo”, de H. G. Wells (2010), o clássico publicado em 1895, uma das primeiras 
obras que boa parte da crítica considera como ficção científica, embora tal definição não seja precisa. Não podemos afirmar que a obra em si seja uma integrante clara da dita cultura primeira dos estudantes. Porém, ela traz alguns elementos hoje bastante presentes no imaginário do jovem por meio de diversos recursos ficcionais: a viagem no tempo, a evolução da espécie humana, entre outros. Por outro lado, poderíamos classificar o livro, sob algum critério, como cultura elaborada, na medida em que se trata de um clássico da literatura escrito por um autor consagrado e reconhecido. Mas entendemos que a questão não é classificar algo como cultura primeira ou elaborada, criando, ou melhor, endossando certa dicotomia entre uma cultura considerada válida e aceitável no cânone escolar, e outra que se pode considerar menor, nos mesmos termos. A questão é que "A Máquina do Tempo" coloca problemas interessantes. O tempo é uma dimensão? Se é, por que não podemos ir para trás ou para frente, indistintamente, como fazemos com as dimensões do espaço? E se fosse possível viajar ao futuro, o que veríamos? A espécie humana, civilizada, sofreria a evolução darwiniana? Essa evolução, necessariamente, nos tornaria seres mais inteligentes ou poderíamos regredir a estágios que consideraríamos mais selvagens? As conquistas tecnológicas poderiam retroceder a níveis ancestrais? Como nos sentiríamos se fôssemos apenas um gado para alimentar uma espécie dominante? E se pensarmos em um futuro longínquo, o que a natureza reserva para nós? Todas essas questões, que qualquer pessoa que tenha lido o romance de Wells irá imediatamente reconhecer no texto da obra, podem, por si, ser interessantes de se tratar com os educandos. Não necessariamente são perguntas que eles mesmos se fariam espontaneamente, mas, ao mesmo tempo que tocam em pontos fundamentais, ligados a problemas sociais, culturais, políticos e éticos do presente.

O substrato, ao mesmo tempo imaginativo e racional, em que a obra coloca tais questões é típico da ficção científica: insere o leitor no mundo imaginário e coloca-o diante dos dilemas. Por mais que apresente uma certa visão, coerente com a ciência ficcional que propõe, não apresenta respostas, mas possibilidades alternativas que nos induzem a pensar em outras. A física, de fato, não permite a viagem temporal nos moldes propostos, nem tampouco a física da época de Wells. Mas ele recria uma física consistente e extrai dela consequências plausíveis. Da mesma forma, não temos dados para afirmar que rumos a evolução da espécie humana pode seguir, muito embora Wells procure seguir de perto alguns pressupostos da teoria darwiniana. Ocorre que, em nenhum dos casos o foco da atenção se volta para as teorias, as máquinas, as coisas, os seres. É da articulação da experiência humana imaginável e possível, em tais condições igualmente imagináveis e potencialmente possíveis, que ele cria sua narrativa. Dessa forma, "A Máquina do Tempo" fala sobre o presente histórico porque propões questões e preocupações contemporâneas a ela, e representa alegoricamente determinadas vertentes observadas e até explicitadas pelo autor em seu contexto. Mas, ao mesmo tempo a história fala sobre um futuro, um futuro que não é possível prever, mas sobre o qual é possível conjecturar, produzir hipóteses, resguardar-se ou desejá-lo, e que acaba, de um modo ou de outro, constituindo um programa de ação sobre o presente.

Dessa forma, em uma situação educativa, seja na sala de aula, seja em um ambiente educativo não formal, ou, mesmo, em outras modalidades de educação em ciências, uma tal obra não seria um meio para estudar a teoria de Darwin ou a física relativística, mas seria uma forma de colocar em pauta as questões sociopolíticas, ligadas diretamente a dilemas sociais, implícitos em tais formulações teóricas. "A Máquina do Tempo" deixa de ser um simples recurso instrucional para ser objeto de estudo, da obra em si, do porque essa obra foi produzida 
naquele contexto, de como se explicam e se abordam as questões que ela propõe e o que ela diz sobre nós mesmos. Ao mesmo tempo, ela não perde seu caráter de fruição, de prazer e de entretenimento, porque é trazida para o contexto educativo com um sentido, com motivação, ligada a questões presentes e pertinentes. Se a prática concreta trouxer "A Máquina do Tempo" ou qualquer outra leitura, filme ou recurso como uma mera imposição desconectada de todo esse contexto, todo o potencial que ela proporcionar estará perdido. No caso de uma obra de ficção científica, o sentido está em perceber quais são as questões, as possibilidades propostas, o exercício de experimentação mental sociotecnológico e os problemas éticos propostos; e verificar de que modo podermos articulá-los às discussões conceituais da ciência que estamos abordando, tendo em mente que as possibilidades são múltiplas e muito mais complexas do que quando estamos manejando um produto didático especialmente produzido para a nossa atividade didática a respeito de um assunto determinado qualquer. Assim que "A Máquina do Tempo" pode ser levada à aula pela professora de física ou de biologia, mas, também, pelo de história ou geografia, ou por todos ao mesmo tempo, em um projeto interdisciplinar, um trabalho extraclasse, ou, mesmo, em exposições em um museu de ciências. Em todos os casos, reduzi-lo a uma única dimensão significa destruir suas possibilidades mais interessantes. Se o educador não se sente em condições de ensinar sobre a teoria de Darwin ou sobre o contexto vitoriano da produção de Wells, isso não implica ignorar completamente tais temas, e sim articulá-los às interessantes discussões científicas e suas implicações éticas, sociais, culturais e políticas que a obra oferece. O mesmo se aplica, evidentemente, a um número imenso de obras de ficção científica, sejam elas romances, contos, filmes, jogos eletrônicos, histórias em quadrinhos ou outra forma qualquer em que o questionamento crítico imaginativo do gênero possa propor.

\section{Referências}

ARISTÓTELES. Metafísica: ensaio introdutório, texto grego com tradução e comentário de Giovanni Reale. 2. ed. São Paulo: Loyola, 2005. v. 2.

ASIMOV, I. No mundo da ficção científica. Rio de Janeiro: Francisco Alves, 1984.

BORGWALD, J. M.; SCHREINER, S. Classroom analysis of rotating space vehicles in 2001: a space odissey. The Physics Teacher, College Park, v. 31, n. 7, p. 406-409, 1993.

BRAKE, M.; THORNTON, R. Science fiction in the classroom. Physics Education, Bristol, v. 38, n. 1, p. 31-34, 2003.

BROOKE-ROSE, C. A rhetoric of the unreal: studies in narrative and structure, especially of the fantastic. Cambridge: Cambridge University Press, 1981.

BRUNNER, J. The educational relevance of science fiction. Physics Education, Bristol, v. 6, n. 6, p. 389-391, 1971. 
DARK, M. Using science fiction movies in introductory physics. The Physics Teacher, College Park, v. 43, n. 7, p. 463-465, 2005.

DUBECK, L. W.; TATLOW, R. Sci-fi in the classroom: making a "deep impact" on young people's interest in science. Mercury, San Francisco, v. 27, n. 6, p. 24-28, 1998.

DUBECK, L. W. et al. Finding facts in science fiction films. The Science Teacher, Arlington, v. 60, n. 4, p. 46-48, 1993.

. Science fiction aids science teaching. The Physics Teacher, College Park, v. 28, n. 5, p. 316-319, 1990.

ECO, U. Sobre o espelho e outros ensaios. Rio de Janeiro: Nova Fronteira, 1989.

FRAKNOI, A. Teaching astronomy with science fiction: a resource guide. Astronomy Education Review, Tucson, v. 1, n. 2, p. 112-119, jul. 2002/jan. 2003.

FREIRE, P. Pedagogia do oprimido. 17. ed. Rio de Janeiro: Paz e Terra, 1987.

FREIRE, P.; FAUNDEZ, A. Por uma pedagogia da pergunta. Rio de Janeiro: Paz e Terra, 1985. (Educação e comunicação, 15).

FREUDENRICH, C. C. Sci-fi science: using science fiction to set context for learning science. The Science Teacher, Arlington, v. 67, n. 8, p. 42-45, 2000.

JAMESON, F. Archaelogies of the future: the desire called utopia and other science fictions. London: Verso, 2005.

KUHN, T. S. A estrutura das revoluções científicas. São Paulo: Perspectiva, 1975. (Debates, 115).

LIBÂNEO, J. C. Fundamentos teóricos e práticos do trabalho docente: estudo introdutório sobre pedagogia e didática. 1990. 506 f. Tese (Doutorado) - Pontifícia Universidade Católica de São Paulo, São Paulo, 1990.

MARTÍN-DÍAZ, M. J. et al. Science fiction comes into the classroom: Maelstrom II. Physics Education, Bristol, v. 27, n. 1, p. 18-23, 1992.

NAUMAN, A. K.; SHAW, E. Sparking science interest through literature: sci-fi science. Science Activities: classroom projects and curriculum ideas, Philadelphia, v. 31, n. 3, p. 18-20, 1994.

PIASSI, L. P. O segredo de Arthur Clarke: um modelo semiótico para tratar questões sociais da ciência usando a ficção científica. Ensaio: Pesquisa em Educação em Ciências (Impresso), v. 14, p. 209-226, 2012.

PIASSI, L. P. A ficção científica e o estranhamento cognitivo no ensino de ciências: estudos críticos e propostas de sala de aula. Ciênc. educ. (Bauru), 2013, v. 19, n.1, p. 151-168.

RABKIN, E. The fantastic in literature. New Jersey: Princenton University, 1977.

SHAW, D.; DYBDAHL, C. S. Science and the popular media. Science Activities: classroom projects and curriculum ideas, Philadelphia, v. 37, n. 2, p. 22-31, 2000. 
SNYDERS, G. A alegria na escola. São Paulo: Manole, 1988.

SOUTHWORTH, T. Modern physics and science fiction: a mini-unit for high school physics. The Physics Teacher, College Park, v. 25, n. 2, p. 90-91, 1987.

SUVIN, D. Metamorfosis de la ciencia ficción: sobre la poética y la história de um género literario. Ciudad de México: Fondo de Cultura Económica, 1984.

TALBOT, M. M. Fictions at work: language and social practice in fiction. London: Longman, 1995.

TODOROV, T. Introdução à literatura fantástica. 3. ed. São Paulo: Perspectiva, 2004. (Debates, 98).

VAN DIJCK, J. After the "Two cultures": toward a "(multi)"cultural" practice of science communication. Science Communication, Thousand Oaks, v. 25, n. 2, p. 177-190, 2003.

WELLS, H. G. A máquina do tempo. Rio de Janeiro: Alfaguara, 2010.

ZANETIC, J. Física e cultura. Ciência e Cultura, São Paulo, v. 57, n. 3, p. 21-24, 2005.

Física também é cultura. 1989. 252 f. Tese (Doutorado) - Faculdade de

Educação, Universidade de São Paulo, São Paulo, 1989. 